\title{
IDENTIFICATION OF THE RELATIONSHIP BETWEEN ELECTROPHORETIC BANDING PATTERNS OF PROTEIN IN GRAINS OF WHEAT GROWN UNDER NORMAL AND SALINITY CONDITIONS \\ Alhendawi,Y. A. \\ Faculty of Science, Omer El-Mokhtar University, Libya
}

\begin{abstract}
Gel electrophoresis of protein has become a standard and powerful research tool for application in biochemical sciences. The aim of this study was to develop biochemical genetic marker such as protein electrophoretic profiles which resulted from gene expression to discover the relationship between the strain genotypes and the environmental effect under normal and salinity conditions.

The results showed that appearance, disappearance and intensity variation of banding patterns in grains protein under saline treatments in studied two genotypes.

From SDS- PAGE showed the represented two bands where $\mathrm{Rm}$ was 0.69 and 0.89 which were appeared only under saline treatment in $S_{2}$. In addition represented only one band where $\mathrm{Rm}$ was 0.89 which were appeared only under environmental saline treatment in $\mathrm{S}_{3}$. These results clearly suggested the presence of an association between salt tolerance and the presence of these bands having stability against the environmental salinity.

These results revealed that some bands could be considered as a salt shock protein band which appeared after salt treatments. Finally, the protein electrophoresis system was a reliable system for discriminating strains under variations of environments conditions.
\end{abstract}

\section{INTRODUCTION}

Traditional cultivar identification based on morphological trails requires extensive observations of mature plants (Wrigley. et al., 1987). Gel electrophoresis of protein has become a standard and powerful research tool for application in biochemical sciences.

Electrophoretic assays have been widely used as a rapid and accurate test to identify and characterize different crop cultivars. SDS-PAGE analysis was successfully used for both identification and differentiation of plant cultivars. It is reliably rapid mean for establishing genetic profiles and elucidation of genetic relationships within and between taxa (Aly, et al., 2000; Badr 1995 and Hassan, 2001).

Drought and salinity are the major constraints in crop production and food security, and adversely impact the socio-economic fabric of many developing countries. Wheat production in the Mediterranean region is limited mainly by the scarcity of water resources. Water deficit stress caused by drought and soil salinization, adversely affects plant growth and crop productivity. For these reasons we need various wheat genotypes tolerant to environmental conditions.

The objective of this investigation is to develop biochemical genetic marker such as protein electrophoretic profiles which was the end product of 
DNA to discriminate between these strain genotypes and the environmental effects under normal and salinity conditions.

\section{MATERIALS AND METHODS}

This investigation was carried out at The experimental Format ELHesha and the laboratory of the Faculty of Science, Omar - El - Mokhtar University, Lybia during 2004 / 2005 and 2006.

1) Materials:

The new strain hexaploid wheat is characterized by tolerance to salinity namely $\left(S_{3}\right)$. The $S_{3}$ was produced from EMS treatments of Egyptian cultivar (Giza 157) and the progeny was then subjected to many consecutive selection cycles for resistance to drought and salinity (Abdel-Raheem, 1990). The genotype $S_{2}$ strain was exported from U.S.A during 1994 which was characterized by its highly tolerant to salinity and drought stresses.

Seawater used for irrigation was sampled from sea beach at Derna city with an average of 34.000 p.p.m and dillutes to $50 \%$ concentration. The analysis of normal water and seawater used is given in Table (1).

\section{2) Methods:}

\section{a- Protein extraction:}

Ten randomly chosen dry grains of each strain into treatments were milled separately to fine powder. Protein fractions were extracted using buffer solution (1M tris- $\mathrm{Hcl}$, ph 6.8, $0.25 \mathrm{M}$ EDTA and 10\% SDS).

\section{b- Gel preparation, sample loading and electrophoresis:}

Samples were centrifuged at $14000 \mathrm{rpm}$ for $10 \mathrm{~min}$ in a cooling centrifuge at $4^{\circ} \mathrm{C}$. The supernatants were used for further analysis. Protein fractions were characterized and identified using one - dimensional SDS-PAGE (sodium dodecyl sulfate - polyacrylamid gel electrophoresis) technique. Slab gels (12.5\%) were prepared according to Laemmli (Laemmli, 1970).

The destained gel was analyzed by using the Biogen gel analysis software, VILBER Inc., France.

\section{RESULTS AND DISCUSSION}

The SDS- DAGE is the most widely used technique for analyzing mixture of protein. Proteins are separated essentially on the basis of their size. The electrophoretic patterns (SDS-PAGE) for water soluble proteins (albumin and globulin) of two wheat strains are illustrated in Fig. 1 and Table 2. From the SDS-PAGE analysis of water soluble proteins, bands were recorded with different number of bands and relative mobilites $(\mathrm{Rm})$.

A total number of 53 protein bands, with molecular weight ranging between 212.0 and $40.0 \mathrm{KDa}$ were recorded in the electrophenograms of the strains studied. SDS-PAGE profiles showed slight differences at high and low molecular weights and high differences at mid molecular weights. The highest number of bands (15) was recorded in $S_{3}$ (saline) and the lowest number (11) was recorded in $\mathrm{S}_{2}$ (normal).

The electrophoretic banding patterns of protein under normal and saline treatments reveled that the general variation between the normal and 
saline treatments represented in the two bands which $\mathrm{Rm}$ was 0.69 and 0.89 which were appeared only under saline treatment in $\mathrm{S}_{2}$. On the other hand in $\mathrm{S}_{3}$ the electrophoretic banding patterns of protein under normal and saline treatments reveled that the general variation between the normal and saline treatments represented in only one band which $\mathrm{Rm}$ was 0.89 was appeared only under saline treatment. These results clearly suggested the presence of an association between salt tolerance and the presence of this bands. These results confirmed the finding of Garcia (1986) who noted that some bands could be considered that as effect of environmental salinity.

Table (1): Analysis of normal water and seawater used for irrigation of experiments in El- Hesha

\begin{tabular}{|l|c|c|}
\hline Analysis & EC & pH \\
\hline Normalwater & 1300 & 7.28 \\
\hline Seawater & 34000 & 8.68 \\
\hline
\end{tabular}

Storage proteins in endosperm of wheat grain represent over $80 \%$ of the whole quantity of proteins in grain, these proteins are not soluble in water at neutral $\mathrm{pH}$ value. Storage proteins are either soluble in $70 \%$ ethanol (gliadins) or insoluble (glutenins). Glutenins have a wide spectrum of molecular weight of 50.000 to several millions Daltons. It is assumed that, the genes which synthesized subunits of glutenin are on the long arms of the chromosomes 1B, 1D ad 4D (Javornik, 1985).

In general, the electrophoretic separation of water soluble protein indicated the presence of a wide genetic variations among the studied wheat cultivars supported the presence of relationship between molecular markers and environmental conditions. These results agreed with those of Chen, et al., (1996). They found differences in electrophoretic patterns of soluble proteins and suggested that these differences could be due to the environmental effects for a long time ago and may use effectively in the identification of wheat cultivars. Our results are also in accordance with those of Perovic, et al. (1998).

The analysis of a large number of wheat cultivars by means of SDSPAGE has proved that all loci display a large number of allelic variations (Payne, 1982). He also demonstrated that in hexaploid wheat there are 3 alleles: the allele a controls the synthesis of the subunit 1 , the allele (b) for the synthesis of the subunit 2 and the allele $c$ is not translated into a protein visible on gel suggested the presence of an interaction between the effect of saline environmental condition and the regulation mechanismof the protein synthesis. This results show that protein patterns obtained by SDS-PAGE may be used as a sufficient tool or differentiation of the studied cultivars by comparing the amount and quality of protein bands (Fig. 1). These results revealed that some bands could be considered as a salt shock protein band which appeared after salt treatments. Finally, the protein electrophoresis system was a reliable system for discriminating strains under variation of environmental conditions. 
Table (2): Comparative analysis of relative No. of bands and mobility rate $(\mathrm{Rm})$ of protein bands of two wheat strains separated using SDS-PAGE technique

\begin{tabular}{|c|c|c|c|c|}
\hline Genotypes & & & & \\
\hline Characte & Normal water & Saline water & Normal water & Saline water \\
\hline No. of bands & 1 & 1 & 1 & 1 \\
\hline & 2 & 2 & 2 & 2 \\
\hline & 3 & 3 & 3 & 3 \\
\hline & 4 & 4 & 4 & 4 \\
\hline & 5 & 5 & 5 & 5 \\
\hline & 6 & 6 & 6 & 6 \\
\hline & 7 & 7 & 7 & 7 \\
\hline & 8 & 8 & 8 & 8 \\
\hline & 9 & 9 & 9 & 9 \\
\hline & 10 & 10 & 10 & 10 \\
\hline & 11 & 11 & 11 & 11 \\
\hline & - & 12 & 12 & 12 \\
\hline & - & 13 & 13 & 13 \\
\hline & - & - & 14 & 14 \\
\hline & - & - & - & 15 \\
\hline $\mathrm{Rm}$ & 0.02 & 0.02 & 0.02 & 0.15 \\
\hline & 0.19 & 0.19 & 0.19 & 0.23 \\
\hline & 0.24 & 0.23 & 0.21 & 0.27 \\
\hline & 0.29 & 0.23 & 0.26 & 0.32 \\
\hline & 0.35 & 0.30 & 0.30 & 0.36 \\
\hline & 0.38 & 0.32 & 0.40 & 0.40 \\
\hline & 0.48 & 0.35 & 0.45 & 0.45 \\
\hline & 0.55 & 0.38 & 0.48 & 0.48 \\
\hline & 0.69 & 0.45 & 0.58 & 0.50 \\
\hline & 0.87 & 0.48 & 0.63 & 0.56 \\
\hline & 0.91 & 0.55 & 0.65 & 0.63 \\
\hline & - & 0.69 & 0.76 & 0.71 \\
\hline & - & 0.89 & 0.87 & 0.72 \\
\hline & - & - & 0.90 & 0.77 \\
\hline & - & - & - & 0.89 \\
\hline
\end{tabular}

212.0 KDa

116.0 KDa

97.4 KDa

66.2 KDa

$57.2 \mathrm{KDa}$

40.0 KDa

Fig. (1): SDS-PAGE patterns of two wheat strains.

( KD=kilo Dalton )

1: Marker (high range - Amersco Inc. USA)

2: $S_{2}$ (normal) , 3: $S_{2}$ (saline) , 4: $S_{3}$ (normal) , $5: S_{3}$ (saline) 
A distance matrix between strains (Table 2) shows an average distance range from 0.00 to 0.29 with a mean of 0.145 . Thus, the strains tested in this study highly divergent (mean $>0.5$ ) at the protein level. The smallest distance value was observed between $S_{2}$ (normal) and $S_{2}$ (saline) strains which appear to be the most similar strains and can be closely regrouped. The maximum distance value of 0.29 , indicating a great dissimilarity, is observed between $\mathrm{S}_{2}$ (saline) and $\mathrm{S}_{3}$ (saline).

All he other strains display different intermediate levels of similarity and are grouped with the other ones.

Table (3): Genetic distances among the two strains of wheat.

\begin{tabular}{|l|c|c|c|c|}
\hline Genotypes & $\mathbf{S}_{2}$ Normal & $\mathbf{S}_{2}$ Saline & $\mathbf{S}_{3}$ Normal & $\mathbf{S}_{3}$ Saline \\
\hline $\mathrm{S}_{2}$ Normal & 1.00 & - & - & - \\
\hline $\mathrm{S}_{2}$ Saline & 0.22 & 1.00 & - & - \\
\hline $\mathrm{S}_{3}$ Normal & 0.00 & 0.25 & 1.00 & - \\
\hline $\mathrm{S}_{3}$ Saline & 0.00 & 0.29 & 0.00 & 1.00 \\
\hline
\end{tabular}

The genetic divergence among SDS-PAGE of protein patterns from the cultivars under investigation was obtained by linkage dendrogram which provides a visual idea about clustering and homology present between lanes which are used on the extent of relative dissimilarity among sample genotype. The homology between four lanes were grouped into three clusters. The $1^{\text {st }}$ contained $\mathrm{S}_{2}$ (saline) and $\mathrm{S}_{3}$ (saline) and the homology between them was about $28 \%$. While the $2^{\text {nd }}$ contained $S_{3}$ (normal) which related to the $1^{\text {st }}$ cluster with homology about $24 \%$ between them. S2 (normal) has no linkage with any one. So, we observed that $S_{2}$ (saline) and $S_{3}$ (saline) \& $S_{3}$ (normal) have a relationship together than that of $S_{2}$ (normal) which has no linkage with any one (Fig. 2).

Fig. (2): Dendrogram presentation of two strains of wheat.

$\begin{array}{ll}\text { 2: } S_{2} \text { (normal) } & 3: S_{2} \text { (saline) } \\ 4: S_{3} \text { (normal) } & 5: S_{3} \text { (saline) }\end{array}$




\section{REFERENCES}

Abdel-Raheem, A; (1990): Genetic studies on salt tolerant mutations indused by EMS in wheat Triticum aesitivum L. J. Agric. Res. Tanta Univ., 16 (1): $70-79$

Aly, M.A.M; N.A.K.F. Rashed and H.Z. Hassan (2000): Genetic variability and assessment of relationship among some Egyptian rice (Oryaza Sativa L.) cultivars as revealed by SDS-proteins and RAPD-PCR analysis. Egypt. J. Genet. Cytol., 29: 71-87.

Badr, A. (1995): Electrophoretic studies of seed proteins in relation to chromosomal criteria and the relationship of some taxa of Trifolium. Taxon, 44: 183-191.

Chen, D. M; L. F. Filipps and L.F. De Filippis. (1996): Application of genomic DNA and RAPD-PCR in genetic analysis and fingerprinting of various species of wheat and woody trees. Aust. Forest, 59: 46-55.

Garcia, A.L; A. Torrecillas, A. Lean and C.M. Ruiz Sanchez (1986): Biochemical indicators of the water stress in maize single seedlings. Biologia Plantarum., 29 (1): 45-48.

Hassan. H.Z. (2001): Genetic fingerprinting and relationships of some lentil (Lens esculenta Moench) cultivars based on protein and DNA polymorphism. J. Union Arab Bio 1, 11: 11-31.

Javornik. B, (1985): Electrophoretic polymourphousis of proteins in wheat. Doctoral dissertation, biotechnical faculty, Ljubljana.

Laemmli, U.K. (1970): Cleavage of structural proteins during the assembly of the head of the bacteriophaye T4. Nature, 227: 680-685.

Payne. J. (1982): The genetics of gliadins and glutenin, the major storage proteins of the wheat endosperm. Qualities plant P1. Fds. Hum. Nutr., 31: 229-241.

Perovic D; Y. Yan; S. Prodanovic; M. Vracarevic and D. Zoric (1998): Characterization of spring barely cultivars by hordein seed storage protein analysis. Rachis. 17: 6-9.

Wrigley, C.W; Batey. I.L and Skerrit (1987): Complementing traditional methods of identifying cereal varieties with novel procedures. Seed Sci. Technol., 15: 679-688.

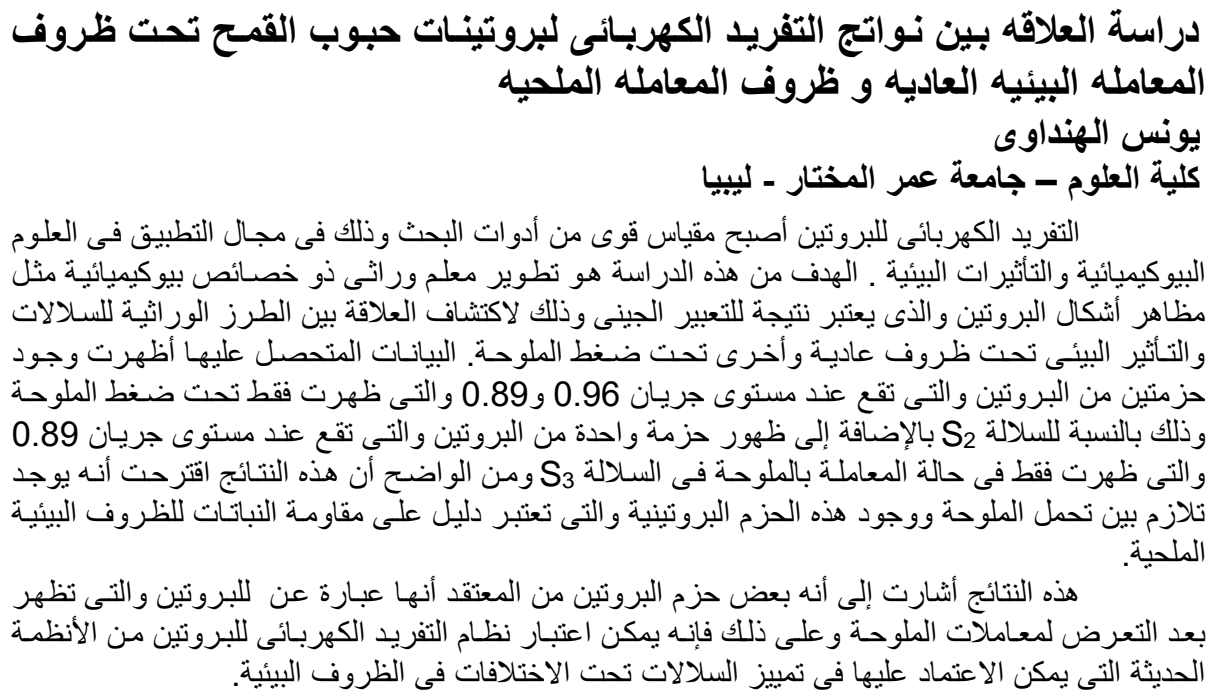


J. Agric. Sci. Mansoura Univ., 32 (8), August, 2007 